\title{
Determining the Lithium and Calcium Concentrations in Canned Tuna Fish in Iran
}

\author{
Mona Daraei ${ }^{1}$, Heibatullah Kalantari ${ }^{2}$, Zahra Nazari Khoragani ${ }^{3}$ \\ ${ }^{1}$ Arvand International Division, Ahvaz Jundishapur University of Medical Sciences, Ahvaz, IR Iran \\ ${ }^{2}$ Department of Toxicology, Pharmacy School, Ahvaz Jundishapur University of Medical Sciences, Ahvaz, IR Iran \\ ${ }^{3}$ Nanotechnology Research Center, Pharmacy School, Ahvaz Jundishapur University of Medical Sciences, Ahvaz, IR \\ Iran
}

Correspondence: Mona Daraei, Arvand International Division, Ahvaz Jundishapur University of Medical Sciences, Ahvaz, IR Iran. E-mail: mona.daraei141@gmail.com

$\begin{array}{lc}\text { Received: July 16, } 2021 & \text { Accepted: August 15, } 2021 \quad \text { Online Published: August 17, } 2021 \\ \text { doi:10.5539/ijc.v13n2p35 } & \text { URL: https://doi.org/10.5539/ijc.v13n2p35 }\end{array}$

\begin{abstract}
Backgrounds and aims: Nutrition is the main way to receive the trace elements that human body needs. Lithium (Li) and calcium (Ca) are two trace elements, which have important roles in human body. There are a few studies about the amounts of calcium and lithium in canned tuna fish. The aim of this study was to determine the concentrations of calcium and lithium in canned tuna fishes.
\end{abstract}

Materials and Methods: To this aim, 150 samples of canned tuna fishes from two well-known brands (Majid and Poolak), marketed in Khuzestan province of Iran, were obtained. Li contents of the samples were measured by atomic absorption spectrometry (AAS) with atomization in graphite furnace. Ca contents of the samples were measured by AAS using nitrous oxide-acetylene flame.

Results: The mean concentrations of calcium in canned tuna fish of Majid and Poolak brands were 448.47 and 398.22 $\mathrm{mg} / \mathrm{kg}$, respectively. Additionally, the mean concentrations of lithium in canned tuna fish of Majid and Poolak brands were 38.42 and $39.67 \mathrm{mg} / \mathrm{kg}$, respectively. The mean concentration of calcium in the investigated canned tuna samples fish was lower than provisional tolerable intake (PTI) per day (1000 ppm) set by World Health Organization (WHO) and Environmental Protection Agency (EPA). However, the mean concentration of lithium in the studied canned tuna fish samples was higher than PTI/day (0.650- $3.1 \mathrm{ppm})$ Set by EPA.

Conclusion: The results of current study showed that the marine food industries need a more-precise and serious monitoring by public health organizations. Additionally, protecting the marine environment from pollutions is an obligation that needs the attention of related organizations and authorities.

Keywords: lithium, calcium, canned tuna fish, atomic absorption spectrometry

\section{Introduction}

Consuming healthy natural foods has a great importance for the entire society. In this regard, receiving sufficient amounts of trace elements and avoiding the excess amounts of these elements is an important factor, which should be carefully monitored. Seafood products are important sources of the trace elements (Guérin; et al., 2011). Due to the release of toxic chemicals from point and non-point pollution sources into surface waters, rivers, lakes and finally into seas, marine animals are affected. As a result, nutritionists are concerned about potential health threats related to consumption of the marine animals as seafood. Therefore, it is necessary to monitor the pollution levels of the marine environment and seafood.

Nowadays, using lithium (Li) is rapidly increasing due to its importance as a vital strategic resource for national economy and protection (Liu; et al., 2015).Li is an element which appears rather in small amounts both in the environment and in the human tissues or body fluids. Li plays key roles in many important vital functions. Li possesses a wide variety of biochemical functions. For example, it settles in the structure of several enzymes, hormones, vitamins, and growth factors (Shaldubina; Agam; Belmaker, 2001; Shorter, 2009). Li is found in variable amounts in foods. Main food sources of Li are grains and vegetables; in some geographical areas, the drinking water also provides significant amounts of lithium. Thus, the human dietary lithium intakes depend on the geographical location and the type of foods 
consumed (Schrauzer, 2002). Many studies consider Li as an essential element; so that, $1000 \mu \mathrm{g} / \mathrm{day}$ of it has been suggested as provisional RDA for a person with $70 \mathrm{~kg}$ weight (Schrauzer, 2002). receiving excess amounts of lithium via foods may induce lithium toxicity, which include several serious clinical manifestations (e.g. Cardiovascular manifestations and permanent neurological deficits) (Zyoud; et al., 2017).

The calcium (Ca) function and its role in the body is well known and expansively defined in literature. It is the most abundant mineral within the body, of which almost $99 \%$ happens in the bones and teeth as deposits of calcium phosphates. The remaining $1 \%$ in the soft tissue and body fluids has very important regulatory functions (Nabrzyski; Gajewska, 2002). The calcium ion $\left(\mathrm{Ca}^{2+}\right)$, released from intracellular stores, controls numerous cellular procedures, including cardiac and skeletal muscle contraction, synaptic transmission and metabolism (Santulli; R Marks, 2015). It is recommended that elderly men and women get calcium at the dose $1000-1200 \mathrm{mg} / \mathrm{day}$, for maintaining their bones healthy. However, the average intake of calcium via diet is 700-900 mg/day for the western countries, and even fewer in Asia and Africa. Accordingly, old people need to receive calcium via consumption of supplements to meet these recommendations. The recommendations for receiving sufficient amounts of calcium is widely applied in western countries. So that, $30-50 \%$ of old women receive calcium supplements. However, several clinical trials reported that calcium supplements at doses higher than $2000 \mathrm{mg}$ /day lead to adverse effects, including cardiovascular events, kidney stones, and hospital admissions for acute gastrointestinal symptoms. Thus, old people are encouraged to keep their bones healthy by improving their calcium intake via consumption of appropriate food instead of taking supplements. By increasing the dietary calcium intake to the recommended level of $>1200 \mathrm{mg} /$ day the risk of fractures is decreased significantly without suffering the adverse effects of calcium supplements (Bolland; et al., 2015).

Recent studies indicate the heavy metals pollution of seas and seafood in many regions of the world, including Iran (Bat; Arici, 2018; Sattari; et al., 2020; Supriya; et al., 2020). The polluted sea food may lead to serious health problems in the people who consume them. Therefore, it is important to prevent and monitor the pollution in seafood products.

According to the literature above, the present study aimed to evaluate the concentrations of two elements, calcium and lithium, in canned tuna fish as an important food source of local population at Khuzestan province of Iran.

\section{Materials and Methods}

\subsection{Materials and Preparing Standard Solutions}

Chemicals were purchased from Chem Lab and Merck Companies. All the glassware and plastic ware were put in nitric acid ( 0.1 molar) for 24 hours, then washed twice with deionized water. Stock standard solutions for $\mathrm{Li}$ and $\mathrm{Ca}$ were $1000 \mathrm{mg} /$ lit. Lanthanum (III) nitrate and ammonium nitrate solutions $(1 \% \mathrm{w} / \mathrm{v})$ were used as modifiers for $\mathrm{Ca}$ and $\mathrm{Li}$ respectively, to eliminate the effect of disturbing ions. The lithium standard solutions were prepared in five concentrations $(40,60,80,100,120 \mu \mathrm{g} /$ lit $)$ by diluting the stock standard solution in nitric acid $(0.1 \mathrm{molar})$. The Calcium standard solutions were prepared in six concentrations $(0.1,0.2,0.5,1,3,5 \mu \mathrm{g} / \mathrm{lit})$ by diluting the stock standard solution in Lanthanum(III) nitrate $(1 \% \mathrm{w} / \mathrm{v})$.

\subsection{Preparation of Samples and Standard Samples}

150 samples of canned tuna fish (Majid and Poolak brands) were collected from the local markets in Khuzestan Province, Iran. All of the collected canned tuna fish samples were mixed (each brand separately) and a representative mass $(50 \mathrm{~g})$ was taken and placed in a porcelain crucible for further steps of examination. Samples were transferred into the electrical furnace with controlled temperature $\left(450^{\circ} \mathrm{C}\right)$ for $24 \mathrm{~h}$ to turn them into their ash. Then the ash samples in the crucible was carefully preserved with $100 \mathrm{~mL}$ of concentrated HNO3. By this procedure, the ash samples became readily soluble in water. Sample solutions were stored in washed and dried plastic bottles. The sample solutions were pulverized into spray in the nebulizer and atomized into the nitrous-acetylene flame of the spectrometer. The air oxygen was used as oxidant.

\subsection{Instrumental Analysis}

The content of Li in the samples was determined by atomic absorption spectrometry (AAS) using Varian AA240FS spectrometer (Palo Alto, California, United States). Measurable analysis was performed in the graphite furnace, GTA 120 Graphite Tube Automizer (Palo Alto, California, United States). Measurements were performed in the pyrolytically coated tubes under an atmosphere of the inert gas argon (Ar) in the following conditions: The wavelength was $670.8 \mathrm{~nm}$. The temperature of pyrolysis and atomization were $800^{\circ} \mathrm{C}$ and $2450^{\circ} \mathrm{C}$, respectively. The concentrations used for drawing the calibration curve were 40.0, 60.0,80.0, 100.0, $120.0 \mu \mathrm{g} / \mathrm{L}$. the current within the hollow-cathode lamp (HCL) was $5 \mathrm{~mA}$. The slit width was $0.5 \mathrm{~nm}$. Single-element hollow analytic cathode lamps were used as the radiation source. The determination parameters of Lithium by AAS method is presented in Table 3.

The content of $\mathrm{Ca}$ in the sample was determined by flame atomic absorption spectrometry (FAAS). 
Operating parameters were set as recommended by the manufacturer manual. The spectrometer and the flame conditions were adjusted to yield optimum precision and sensitivity, to maximize absorbance signals and to minimize backgrounds set at $422.7 \mathrm{~nm}$ wavelengths for $\mathrm{Ca}$. the current within the hollow-cathode lamp (HCL) was $10 \mathrm{~mA}$ and the slit width was $0.5 \mathrm{~nm}$.

To establish the precision of the explained and applied analytical procedure, an appropriate validation was performed. The limits of detection (LOD) were used to identify any cross corruption or memory effects from sample preparation (calculated from: $3.3 \times \mathrm{SD} / a$, where: SD standard deviation for blanks; $a$ the slope of calibration curve). Thus, each test run included one reagent blank control. The LODs of $\mathrm{Ca}$ and $\mathrm{Li}$, given that the limit of quantification (LOQ), correspond to Table 2. Unfortunately, there are no suitable certified reference materials for Li content in biological media. Its quantity is reported only in a few material. The instrumental drift was verified in each 100 samples (plus one at the end) by the control of the sensitivity of one calibration standard.

\subsection{Statistical Analyses}

Statistical analyses were performed using SPSS software version20. Results were expressed in the form of mathematics mean (x) $\pm \mathrm{SD}$. Analysis of variance (T test - One Sample) was used to compare results in groups of canned tuna fish (Mann-Whitney test, $p<0.05$ ) and ( Independent Sample T Test) for correlation analysis between variables.

\section{Results}

As shown in table 1, the results of the study showed that mean \pm SD concentrations of Li for Majid and Poolak brands were $38.4 \pm 19.6 \mathrm{ppm}$ and $39.7 \pm 30.3 \mathrm{ppm}$, respectively. Additionally, the mean $\pm \mathrm{SD}$ concentrations of Ca for Majid and Poolak brands were $448.5 \pm 448.3 \mathrm{ppm}$ and $398.2 \pm 268.3 \mathrm{ppm}$, respectively. Other statistical indices are shown in table 1.

Table 1. Li and $\mathrm{Ca}$ content in canned tuna fish, its mean values per $50 \mathrm{~g}$ of canned tuna fish and their range

\begin{tabular}{llll}
\hline Tuna Fish Sample & \multicolumn{1}{c}{ Statistical indices } & \multicolumn{1}{c}{ Li Con.(ppb) } & Ca Con. (ppm) \\
\hline \multirow{2}{*}{ Majid Brand } & Mean & 38.42168 & 448.47464 \\
\cline { 2 - 4 } & Median & 35.52100 & 388.88900 \\
\cline { 2 - 4 } & Variance & 387.506 & 232600.761 \\
\cline { 2 - 4 } & Std. Deviation & 19.685176 & 482.287011 \\
\cline { 2 - 4 } & Minimum & 12.169 & 63.333 \\
\cline { 2 - 4 } & Maximum & 80.956 & 2630.000 \\
\cline { 2 - 4 } Poolak Brand & Range & 68.787 & 2566.667 \\
\cline { 2 - 4 } & Std. Error of Mean & 3.937035 & 96.457402 \\
\hline & Mean & 39.67832 & 282.22200 \\
\cline { 2 - 4 } & Median & 33.26200 & 71997.895 \\
\cline { 2 - 4 } & Variance & 918.486 & 268.324235 \\
\cline { 2 - 4 } & Std. Deviation & 30.306527 & 961.111 \\
\cline { 2 - 4 } & Minimum & 13.399 & 953.333 \\
\cline { 2 - 4 } & Maximum & 134.907 & 53.664847 \\
\cline { 2 - 4 } & Range & 6.061305 & \\
\cline { 2 - 4 } & Std. Error of Mean & & \\
\hline
\end{tabular}

The limits of detection (LOD) and limit of quantification (LOQ) for $\mathrm{Li}$ and $\mathrm{Ca}$ are shown in table 2.

Table 2. limits of detection (LOD), limit of quantification (LOQ) for $\mathrm{Li}$ and $\mathrm{Ca}(\mathrm{mg} / \mathrm{kg}$ )

\begin{tabular}{rrr}
\hline Element & LOD & LOQ \\
\hline $\mathbf{C a}$ & 0.03 & 0.1 \\
\hline $\mathbf{L i}$ & 0.04 & 0.012 \\
\hline
\end{tabular}


Table 3. The parameters for the determination of Lithium by the AAS Method

\begin{tabular}{ccccll}
\hline $\begin{array}{c}\text { Step } \\
\text { No. }\end{array}$ & $\begin{array}{c}\text { Temp. } \\
\left({ }^{\circ} \mathbf{C}\right)\end{array}$ & $\begin{array}{c}\text { Time } \\
(\mathbf{s e c})\end{array}$ & $\begin{array}{c}\text { Gas Flow } \\
(\mathbf{L} / \mathbf{m i n})\end{array}$ & Gas Type & Read \\
\hline $\mathbf{1}$ & 85 & 5 & 3.0 & Normal & No \\
$\mathbf{2}$ & 95 & 40 & 3.0 & Normal & No \\
$\mathbf{3}$ & 120 & 10 & 3.0 & Normal & No \\
$\mathbf{4}$ & 700 & 5 & 3.0 & Normal & No \\
$\mathbf{5}$ & 800 & 1 & 3.0 & Normal & No \\
$\mathbf{6}$ & 800 & 2 & 0.0 & Normal & No \\
$\mathbf{7}$ & 2300 & .8 & 0.0 & Normal & Yes \\
$\mathbf{8}$ & 2300 & 2 & 0.0 & Normal & Yes \\
$\mathbf{9}$ & 2450 & 2 & 3.0 & Normal & No \\
\hline
\end{tabular}

Table 4. Recovery study of $\mathrm{Li}$ and $\mathrm{Ca}$ in canned tuna fish

\begin{tabular}{cccccccc}
\hline $\begin{array}{c}\text { Li Concentration } \\
(\mathbf{p p b})\end{array}$ & Mean of Absorbance & SD & CV & $\begin{array}{c}\text { Concentration } \\
(\mathbf{p p m})\end{array}$ & $\begin{array}{c}\text { Mean of } \\
\text { Absorbance }\end{array}$ & SD & CV \\
\hline $\mathbf{4 0}$ & 0.8796 & 0.0067 & 1.1 & $\mathbf{0 . 1}$ & 0.0047 & 0.0001 & 2.4 \\
\hline $\mathbf{6 0}$ & 1.1175 & 0.0050 & 0.6 & $\mathbf{0 . 2}$ & 0.0076 & 0.0002 & 3.1 \\
\hline $\mathbf{8 0}$ & 1.2970 & 0.0064 & 0.7 & $\mathbf{0 . 5}$ & 0.0171 & 0.0001 & 0.8 \\
\hline $\mathbf{1 0 0}$ & 1.4086 & 0.0123 & 1.2 & $\mathbf{1 . 0}$ & 0.0315 & 0.0002 & 0.6 \\
\hline $\mathbf{1 2 0}$ & 1.5133 & 0.0052 & 0.5 & $\mathbf{3 . 0}$ & 0.0926 & 0.0004 & 0.5 \\
\hline $\mathbf{0}$ & 0.0000 & 0.0000 & 0.0 & $\mathbf{5 . 0}$ & 0.1486 & 0.0004 & 0.2 \\
\hline
\end{tabular}

\section{Discussion}

Current study showed that the amount of $\mathrm{Li}$ in canned tuna fish was less than $40 \mathrm{ppb}(<40 \mu \mathrm{g} / \mathrm{kg})$. this result showed that consuming the canned tuna fish as a meal does not increase the $\mathrm{Li}$ intake to a level higher than the recommended daily intake of lithium (14.3 $\mu \mathrm{g} / \mathrm{kg}$ body weight) for an adult person (Aral; Vecchio-Sadus, 2008). The Li content of the canned tuna fish was also comparable with the Li contents of other food groups (Leblanc; et al., 2005). This finding matches the common sense, since marine foods are not usually among the food sources with the highest Li content. Indeed, cereals, vegetables, and dairy products contain the highest levels of Li. Fortunately, current study showed that the canned tuna fish is a safe food, regarding the Li content and it is not affected by probable metal pollutions of the Persian Gulf.

The results of current study indicated that the amount of $\mathrm{Ca}$ in canned tuna fish was less than $450 \mathrm{ppm}(<450 \mathrm{mg} / \mathrm{kg})$. This amount was consistent with the previous studies, which reported comparable amounts of calcium in tuna fish (Abbey; et al., 2017; Talib; Hariati; Nurhidayati, 2020). The findings indicated that tuna fish is a rich dietary source of $\mathrm{Ca}$, which can supply human daily needs, together with other food groups (Uusi-Rasi; Kärkkäinen; Lamberg-Allardt, 2013).

In this study, the levels of $\mathrm{Li}$ and $\mathrm{Ca}$, in samples of canned tuna fish in local brands of Khuzestan province, was reported. These results showed that there is no risk in canned tuna fish with respect to the concentrations of $\mathrm{Li}$ and $\mathrm{Ca}$ and their recommended daily intake (Fogelholm; research, 2013). These results may provide useful information for measuring of $\mathrm{Li}$ and $\mathrm{Ca}$ intake from this source.

In recent years, fish and its products have became more attractive to human societies, because of their health benefits, compared to the other types of meat. Due to the growing trend of consumption of marine products, especially fish and canned tuna fish, the quality control of these materials is essential for maintaining and improving the health of human communities. Therefore, it is important to monitor these products with respect to positive and negative effects of $\mathrm{Li}$ and $\mathrm{Ca}$ on human health. 


\section{Conclusion}

The canned tuna fish produced by Khuzestan factories were appropriate food sources for Li and Ca dietary intake, while avoiding the toxic effects of receiving excess amounts of the elements. It is also strongly recommended that inclusive and periodic monitoring of the trace and essential metals in the canned tuna fish must be done to ensure the safety and health of the consumers.

\section{Acknowledgments}

This study was supported by Arvand International Division, Ahvaz Jundishapur University of Medical Sciences Ahvaz, Iran.

\section{Conflict of interest}

none

\section{Compliance with Ethics Requirements}

This article does not contain any studies with human or animal subjects.

\section{References}

Abbey, L., Glover-Amengor, M., Atikpo, M. O., Atter, A., \& Toppe, J. (2017). Nutrient content of fish powder from low value fish and fish byproducts. Food Science \& Nutrition, 5(3), 374-379. https://doi.org/10.1002/fsn3.402

Aral, H., \& Vecchio-Sadus, A. (2008). Toxicity of lithium to humans and the environment-A literature review. Ecotoxicology and Environmental Safety, 70(3), 349-356. https://doi.org/10.1016/j.ecoenv.2008.02.026

Bat, L., \& Arici, E. (2018). Chapter 5 - Heavy Metal Levels in Fish, Molluscs, and Crustacea From Turkish Seas and Potential Risk of Human Health. In Food Quality: Balancing Health and Disease, Holban, A. M.; Grumezescu, A. M., eds. (Academic Press), 159-196.

Bolland, M. J., Leung, W., Tai, V., Gamble, G. D., Grey, A., \& Reid, I. R. (2015). Calcium intake and risk of fracture: systematic review. $B M J, 351$. https://doi.org/10.1136/bmj.h4580

Fogelholm, M. J. F. (2013). New Nordic nutrition recommendations are here. 57. https://doi.org/10.3402/fnr.v57i0.22903

Guérin, T., Chekri, R., Vastel, C., Sirot, V., Volatier, J. L., Leblanc, J. C., \& Noël, L. (2011). Determination of 20 trace elements in fish and other seafood from the French market. Food Chemistry, 127(3), 934-942. https://doi.org/10.1016/j.foodchem.2011.01.061

Guérin, T., Chekri, R., Vastel, C., Sirot, V., Volatier, J. L., Leblanc, J. C., \& Noël, L. (2005). Dietary exposure estimates of 18 elements from the 1st French Total Diet Study. Food Additives \& Contaminants, 22(7), 624-641. https://doi.org/10.1080/02652030500135367

Liu, L. F., Zhang, H. W., Zhang, Y. S., Cao, D. M., \& Zhao, X. H. (2015). Lithium extraction from seawater by manganese oxide ion sieve MnO 2 $0.5 \mathrm{H} 2 \mathrm{O}$. Colloids and Surfaces A. Physicochemical and Engineering Aspects, 468, 280-284. https://doi.org/10.1016/j.colsurfa.2014.12.025

Nabrzyski, M., \& Gajewska, R. (2002). Content of strontium, lithium and calcium in selected milk products and in some marine smoked fish. Die Nahrung, 46(3), 204-208. https://doi.org/10.1002/1521-3803(20020501)46:3<204::AID-FOOD204>3.0.CO;2-8

Santulli, G. R., \& Marks, A. (2015). Essential roles of intracellular calcium release channels in muscle, brain, metabolism, and aging. Current Molecular Pharmacology, 8(2), 206-222. https://doi.org/10.2174/1874467208666150507105105

Sattari, M., Vajargah, M. F., \& Bibak, M. (2020). Relationship Between Trace Element Content in the Brain of Bony Fish Species and Their Food Items in the Southwest of the Caspian Sea Due to Anthropogenic Activities.

Schrauzer, G. N. (2002). Lithium: occurrence, dietary intakes, nutritional essentiality. Journal of the American College of Nutrition, 21(1), 14-21. https://doi.org/10.1080/07315724.2002.10719188

Shaldubina, A., Agam, G., \& Belmaker, R. H. (2001). The mechanism of lithium action: state of the art, ten years later. Progress in Neuro-Psychopharmacology and Biological Psychiatry, 25(4), 855-866. https://doi.org/10.1016/S0278-5846(01)00154-3

Shorter, E. (2009). The history of lithium therapy. Bipolar Disorders, 11(2), 4-9. https://doi.org/10.1111/j.1399-5618.2009.00706.x 
Supriya, R. A., Sureshkannan, S., \& Porteen, K. (2020). Investigation of heavy metal concentrations in sea food from three selected landing centers of Chennai coast.

Talib, A., Hariati, A. M., \& Nurhidayati, F. (2020). The mineral content and vitamin d on bone flour fish yellowfin tuna. Journal of Physics: Conference Series, 1517, 012042. https://doi.org/10.1088/1742-6596/1517/1/012042

Uusi-Rasi, K., Kärkkäinen, M. U. M., \& Lamberg-Allardt, C. J .E. (2013). Calcium intake in health maintenance - a systematic review. Food \& Nutrition Research, 57(1), 21082. https://doi.org/10.3402/fnr.v57i0.21082

Zyoud, S. H., Waring, W. S., Sweileh, W. M., \& Al-Jabi, S. W. (2017). Global Research Trends in Lithium Toxicity from 1913 to 2015. A Bibliometric Analysis, 121(1), 67-73. https://doi.org/10.1111/bcpt.12755

\section{Copyrights}

Copyright for this article is retained by the author(s), with first publication rights granted to the journal.

This is an open-access article distributed under the terms and conditions of the Creative Commons Attribution license (http://creativecommons.org/licenses/by/4.0/). 